\title{
Marketing Capability Development in Micro Manufacturing Enterprises
}

\author{
Guven Gurkan Inan'1, Aysegul Eda Kop² \\ ${ }^{1}$ Ardahan University, Ardahan, Turkey \\ ${ }^{2}$ University of Aberdeen, Aberdeen, UK \\ Email: guvengurkaninan@ardahan.edu.tr
}

How to cite this paper: Inan, G.G. and Kop, A.E. (2018) Marketing Capability Development in Micro Manufacturing Enterprises. American Journal of Industrial and Business Management, 8, 1-12. https://doi.org/10.4236/ajibm.2018.81001

Received: December 4, 2017

Accepted: January 5, 2018

Published: January 8, 2018

Copyright ( 92018 by authors and Scientific Research Publishing Inc. This work is licensed under the Creative Commons Attribution International License (CC BY 4.0).

http://creativecommons.org/licenses/by/4.0/

(c) (i) Open Access

\begin{abstract}
Marketing capability is defined as the ability of an organization to understand and fulfil customers' needs at the right time, right place and right cost. Marketing capability is essential for sustainable business performance. Many micro enterprises do not have any marketing strategy and/or have limited marketing activities. A conceptual framework is developed with a view to develop the marketing capability of micro manufacturing enterprises in this research. In this study, four micro manufacturing enterprises were observed over a year. Action research methodology was adopted to test effectiveness of interventions. Some interventions and capabilities were found to be related with marketing capability in micro manufacturing enterprises. Findings showed that empowerment, operational excellence, strategy development and implementation, and collaboration capabilities could enhance marketing capability in micro manufacturing enterprises.
\end{abstract}

\section{Keywords}

Marketing Capability, Micro Enterprises, Action Research

\section{Introduction}

Although companies had mostly focussed on concepts related to production and selling, the importance of marketing is increasingly accepted in the literature [1] [2]. Marketing has become of topical importance especially since it allows the companies to understand customers' needs, the satisfaction of whom is pivotal for their financial success in the market. Previously, companies were able to sell what they produced, and often their sale strategies were successful enough to increase their sales. However, these strategies are increasingly rendered inefficient as a customer-based marketing approach has replaced the prevailing "produce 
and sell" approach.

Nowadays, a greater number of available choices have led the customers to expect more than just a product from the companies. Indeed, evolving marketing environment allows customers to choose the products that can satisfy them not only with their features but also with the whole process, including after-sale services [2]. This shift in customer expectation has intensified the competition in the market. As a result, marketing departments have progressively become critical for company performance in terms of their contribution to the increase sales, profits, and market shares [3]. This is because companies aim to better understand their customers in order to survive in the market and attain financial success. To achieve this, not only the marketing department, but all departments of a company should understand and adopt the marketing concept which is mainly based on satisfying customers' desires and needs in a profitable way. However, marketing approach may vary depending on the size of the company. Although marketing is considered as one of the important factors for success or failure in the market, small companies are often unable to efficiently adopt this marketing approach. As Moller and Anttila [4] emphasize, many small companies perceive the marketing approach through a predominantly product, production and sales-oriented perspective whereby marketing is not regarded as a priority. This approach could be explained by these companies' drive to gain profits from production in a relatively short time rather than focussing on customer needs and competitive environment, an action that requires long-term monitoring [4]. This unusual situation has aroused interest in assessing the marketing capability of micro companies. Although the majority of previous studies focus on either large enterprises or small and medium size enterprises (SMEs), studies on micro enterprises are limited. More research is needed to better understand the factors that may be involved in the decisions related to marketing capability of micro enterprises.

In developing countries, micro manufacturing enterprises are indispensable for various reasons, such as their role in supporting employment, entrepreneurship, wealth creation, and innovation as well as establishing an educated and skilled workforce [5]. Indeed, micro enterprises account for $85 \%$ - $90 \%$ of total businesses in OECD countries [6]. Although the classification of enterprises varies according to different criteria, one of the most widely used criterion when classifying micro enterprises is the number of employees of these companies [7]. However, no standard cut-off value for different categories exists, and the economic environment of the host country creates substantial differences in adopted classifications. For instance, companies with fewer than 2000 employees are classified as SMEs in China, while in Europe this cut-off value sits at fewer than 250 employees. The current study was conducted in Turkey, and has defined SMEs according to the European criteria. In addition, this study defined micro enterprises as companies with fewer than 20 employees.

Micro enterprises face different types of challenges due to issues related to finances, raw materials, marketing, and management, most of which are related to 
their small employee size [8] [9] [10]. It is important to note that, although similarities may exist, micro enterprises differ vastly from large enterprises. Thus, solutions implemented in large enterprises may not be appropriate for micro enterprises. Marketing literature predominantly focuses on the marketing capability of large and SMEs. Micro enterprises are often neglected by researchers. The current study aims to fill this research gap by understanding how micro manufacturing enterprises develop marketing capability.

\section{Marketing Capability}

Marketing capability has an important role in companies' decision-making on especially market related topics [11]. Many definitions exist for marketing capability. For instance, Ripolles and Blesa define marketing capability ([11]) as "a firm's skills and competences relating to market information gathering, sharing and dissemination throughout the organization; launching successful new products, and customer relationship and supplier relationship development." On the other hand, Banterle [12] defines marketing capabilities as "the activities and the processes, involving market research, strategy, planning and evaluation, aimed at reaching the satisfaction of consumers' preferences." Marketing capability could also be defined as the "complex combination of the human resources or assets, market assets, and organisational assets of a firm" ([4]). In this study, we define marketing capability as a company's ability to understand changing customer needs and to meet customers' expectations using tangible and intangible assets.

Marketing capability is important for numerous reasons. Firstly, marketing capability is pivotal for understanding both the market and competitive environment [11]. It could confer key advantages in competitive environments, especially in terms of product differentiation [13] [14]. Indeed, marketing capability is a valuable source for competitive advantage [3] [11] [14], since it allows a company to analyse competitors' marketing strategies, and relevant market issues which can inform its own strategies. Well-developed and integrated marketing strategies can help companies to become more profitable. Companies with a highly developed marketing capability demonstrate a high level of performance [14] [15]. Further, a developed marketing capability enables companies to be more consumer-oriented which results in a better understanding of customers as well as development of successful marketing strategies according to customer needs and the market demands. It has been shown that strong relationships with customers can improve a company's profitability as these relationships allow the company to better satisfy customers' needs and focus on the most profitable customers [3] [11]. Different organisational activities related to marketing capability include market sensing capabilities; market research; market bonding capabilities, such as customer relationship management (CRM); spanning capabilities; information sharing and dissemination throughout the organization; coordination mechanisms to integrate market knowledge into internal processes, and activities to generate new market knowledge ([11]). 
Current marketing literature provides essential knowledge to understand the development of marketing capabilities in large and SMEs; however, to our knowledge, there is no research on the development of marketing capabilities in Micro manufacturing enterprises. Thus, the following research question is formulated to fulfil the gap in the literature:

How do micro manufacturing enterprises develop their marketing capability?

A conceptual framework and propositions were formulated to address this research question. Both internal and external factors affect the marketing capability of companies [15], which is directly related to physical, market, human and organisational resources available to a company [12]. In turn, these resources are influenced by both internal and external factors [4]. Market and technological conditions count as external factors; whereas, organisational and marketing adaptations are internal factors. In this study, both the internal and external dimensions were analysed for their contribution to marketing capability of micro enterprises.

Firstly, internal dimension involves the planning, organisation and management of marketing and the integration of departments ( $\&$ D, marketing, production) in the company. Human assets are central for evaluating internal dimensions. Company employees have various tasks whose coordination may vary according to the changes in the market or environment [15]. The combination of knowledge and skills developed through work experience can improve marketing strategies and capabilities [3] [14]. The number of persons and their expertise in the area are quite substantial for developing marketing strategies and consequently marketing capabilities [4]. The managerial expertise of these human assets may bring success or cause failure to a company. However, small companies can benefit from external human resources to support its internal human assets to achieve success, since they cannot employ a sufficient number of experts in the company. In micro enterprises, command and control culture is dominant [16], whereby owners/managers undertake more operational activities than strategic activities. These owners/managers avoid sharing their authority with employees, a tendency that prevents the company to focus on strategic activities.

Proposition 1: Micro manufacturers without empowerment problems should perform better in marketing capabilities.

Secondly, according to the findings of their research, Moller and Anttila [4] found that a more structured marketing organisation can perform better than unstructured ones. Successful ones have more flexibility in planning, and follow better operational planning and management strategies [3] [4]. Although micro enterprises may not achieve well-organized operational planning, they can use this flexibility to their advantage. Specifically, their small size can be an advantage, since it enables relatively easy and quick decision-making in unforeseen situations. However, many micro manufacturing enterprises face low productivity, long lead times, and limited operational improvement activities. Micro enterprises work in very high competitive markets in which customers seek to wait 
less to receive a product.

Proposition 2: Micro manufacturers with operational excellence activities should perform better on marketing capabilities.

Thirdly, external dimension refers to a company's ability to managing a company's relationship with its external partners including their customers. Bonding capabilities help to create and increase commitment in the market and reach out to external partnerships [11] such as customers, distribution channels, suppliers and other external stakeholders to access available technology. This information exchange with external partners is valuable in increasing the company's competitive advantage and improving its strategies [17]. Especially customer-related marketing capability helps increase the understanding of the customers and markets and to develop successful customer strategies. Competitor-related marketing capability can help understand key competitors' strategies. Environmental turbulence such as "increased risk, uncertainty, decreased ability to forecast, and fluid firm and industry boundaries" impact the market performance of the companies, particularly that of small size companies ([15]). This environmental turbulence increases the competitiveness in the market, since market conditions change and shape rapidly. Hence, these conditions force the companies to react to the market changes quickly and may also create new opportunities [14] [15]. In this environment, companies that have marketing strategies which are built on competitive advantages, differentiating marketing strategies, following the customer and market needs, and up-to-date technology are more likely to succeed since these allow them to quickly adapt their strategies to the current market conditions ([15]).

Proposition 3: Micro manufacturers that have active networking and collaboration activities should perform on marketing capabilities.

Lastly, to build an efficient strategy for long-term success, management teams need to carefully analyse the environment, customers, and competitors [14]. Repeating the process provides more experience and expertise to the employees [14]. By combining employees' experience, skills and company resources, companies can develop strategies which strengthen their marketing capabilities [3] [15]. Further, this combination can help satisfy customer needs. However, SMEs face difficulties in adapting to market changes and competing with larger companies [12]. This difficulty can be explained by problems in adaptation of market changes and compete with larger companies [12]. For instance, Banterle has argued that most micro enterprises among the 60 studied food industry companies in Belgium, Italy and Hungary were not successful in developing efficient marketing strategies due to their limited marketing research capabilities and inability to accurately analyse markets [12]. As a result, these companies could not develop their strategies according to the customer preferences and market needs. However, in some cases micro enterprises can perform better than bigger size companies [12]. This shows that a small company size is not an absolute barrier to achieving a better performance in marketing [12], although both size and resources may limit strategy development and implementation activities. Strategy 
development and implementation is essential for marketing capability. Micro enterprises have short-term plans to survive but marketing capability requires long term strategy to create a loyal customer base and bring new customers to business.

Proposition 4: Micro manufacturers that have strategy development and implementation activities should perform better on marketing capabilities.

These factors show that factors including empowerment inside and outside the company, operational excellence inside the company, networking and collaboration among the departments inside the company may increase the competence of marketing capabilities and help companies develop and implement strategy. Figure 1 details the conceptual framework which was formulated based on current literature and propositions detailed above.

\section{Methodology}

Developed framework and positions were assessed using action research methodology. Reason and Bradbury [18] define action research as "a participatory, democratic process concerned with developing practical knowing in the pursuit of worthwhile human purposes, grounded in a participatory worldview which we believe is emerging at this historical moment. It seeks to bring together action and reflection, theory and practice, in participation with others, in the pursuit of practical solutions to issues of pressing concern to people, and more generally the flourishing of individual persons and their communities". Action research methodology enables researchers to test propositions in organizations by creating a change and observing its influences. Further, action research enables a researcher to understand how events occur rather than only providing insight on what is occurring [19].

As illustrated in Figure 2, action research methodology has five stages [20]. Adhering to these stages, four micro manufacturing enterprises were observed over a year in this study. These companies are selected based on following criteria;

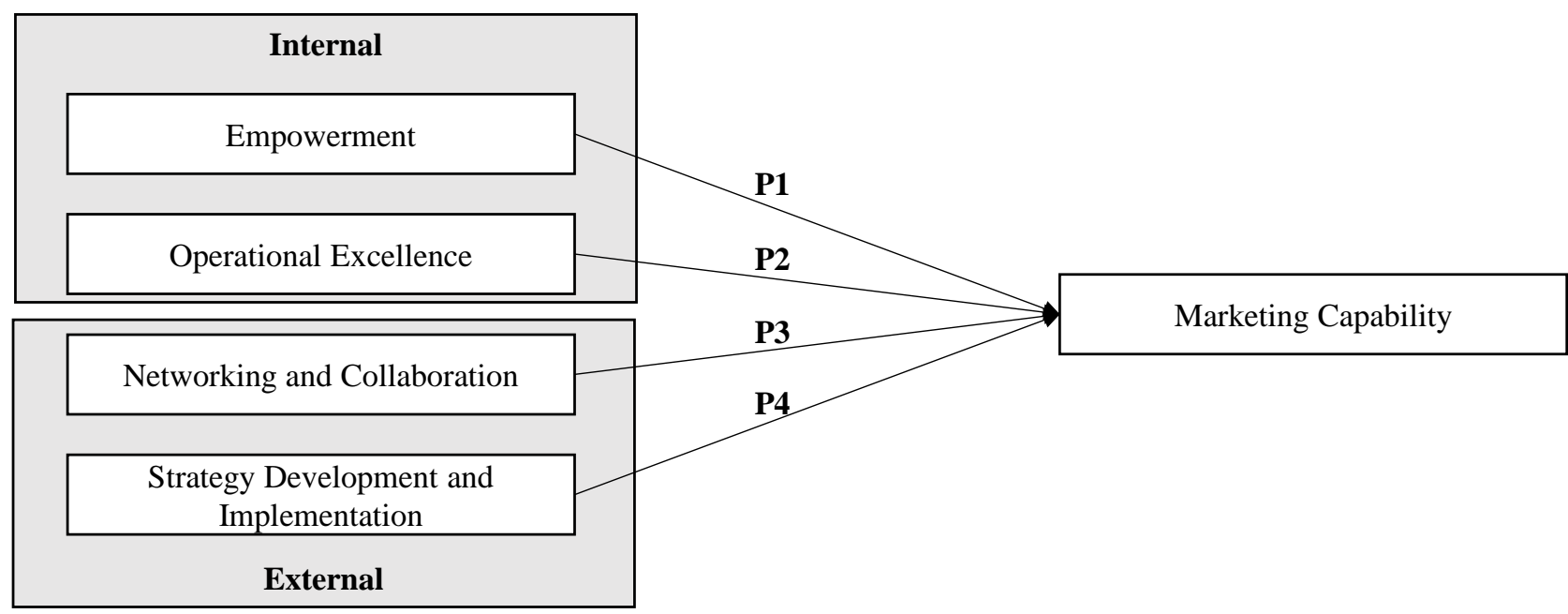

Figure 1. Conceptual framework. 


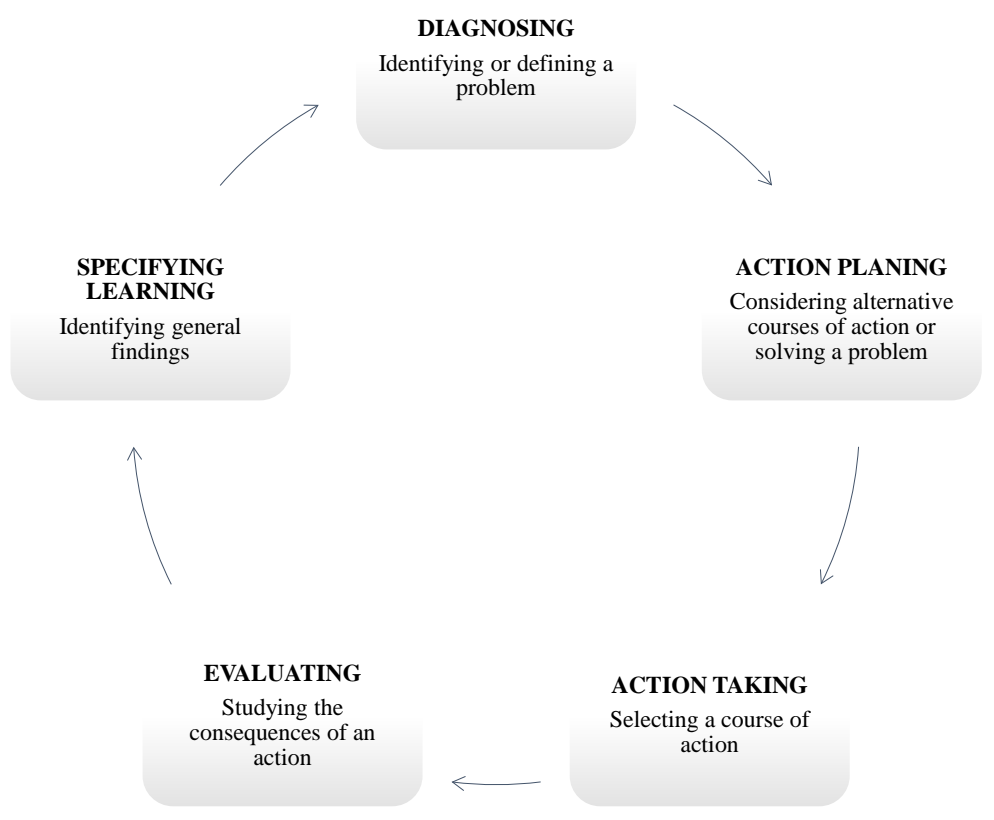

Figure 2. Cycle of action research methodology.

size, industry, willingness to participate and development. We contacted with 16 companies via regional development agency and 4 of them accepted to collaborate with us. First, marketing problems were identified in the diagnostic stage. An action plan was designed to prevent problems that obstruct the growth of marketing capability. In the action taking stage, suggested interventions were (or not). In the evaluation stage, influences of implemented interventions were observed; the reasons for not implementing interventions were identified, and necessary adjustments were suggested. Data were collected through semi-structured interviews, observations and documentations. Development of marketing capability was measured by before and after analysis.

\section{Data Analysis and Findings}

Collected data was analysed using within-case and cross-case analysis methods. Within-case analysis provides deep understanding of each case. Company A was furniture Manufacturer Company for 40 years. It was a family business, and at the time of the study, the second generation was managing the all company assets. It was observed in the first diagnostic stage that marketing capability was not developed in Company A. There were various reasons for undeveloped marketing capability in Company A: the manager/owner did not have time for marketing activities; operation lead times were longer than customer expectations, and no marketing strategy existed. Certain interventions were developed and suggested to address barriers to improving the company's marketing capability. Results were positive, and increasing trends in annual sales were observed.

Company B was a 10-year-old manufacturer of door and windows, and plastic and metal accessories. They had a marketing strategy and sales activities but their operations did not support the sales. They had along lead time (25 - 30 
days). Certain interventions were designed to increase production capacity and reduce lead time. As a result, lead time reduced to $17-21$ days and new equipment was purchased to produce new products.

Company $\mathrm{C}$ was a cartoon box producer for regional market for 17 years. They competed with national size companies in the local market. They had a marketing strategy which led them to lose customers due to the price. The market place requires low costs, quick times, and several logistics solutions. Certain interventions were designed to develop marketing capability. As a result, some of old customers returned with right approach, production costs were reduced $5 \%-15 \%$ depends on its production processes, and logistics supports provided some big customers. Company D has been organic jam manufacturer for 2 years. Owner was mid-age woman who has had some support from local government and non-government support organizations for start-up. Company had needed to gain new customers as soon as possible to survive. A marketing strategy was developed to place products in local super markets; collaboration and networking activities were suggested with tourism tours and hotels to reach tourists. As a result, Company D increased their sales number within a year. All identified issues, suggested interventions, implementation status, and results are demonstrated at Table 1.

Cross-case analysis provides comparisons to understand similarities and differences between cases. Similar problems were identified at micro manufacturing companies such as lack of marketing strategy or wrong marketing strategy, lack of slack time for marketing activities, long lead times and low productivity. Strategy development training provides essential data gathering, analysing, and developing strategy stages. All companies performed very well at strategy development and all companies have a marketing strategy. For instance, Company $\mathrm{C}$ sales team was informed to explain manufacturing costs to customers which can get less coloured and complex boxes with less money. On the other hand, Company $\mathrm{D}$ were trying to sell wrong products at wrong location such as expensive organic products were tried to be sold in university students' neighbourhood but practical, easy to cook or ready to eat products are sold in the same location now. Lack of slack time was another issue in micro manufacturing enterprises. Owner/manager has focused on operations to command and control all the production and logistic processes, he or she could not find time for marketing, strategy development, and/or networking and collaboration activities. For instance, Company A owner had more sales time after he changed the organization structure and created slack time for himself. In addition, long lead times were another problem which cause losing existing or potential customers. Operational excellence tools can be adjusted for micro manufacturing enterprises. Operational excellence also reduces the lead time. For instance, Company B was not happy to lose customers because of its long lead times. Its operational excellence improvement enabled them to reduce lead time significantly and they can sell more products to more customers now. 
Table 1. Issues, interventions, implementation, and results.

\begin{tabular}{|c|c|c|c|c|}
\hline Company & Issues & Interventions & Implemented & Results \\
\hline \multirow{6}{*}{ Company A } & \multirow{6}{*}{$\begin{array}{l}\text { A lack of } \\
\text { marketing } \\
\text { strategy or } \\
\text { marketing } \\
\text { activities }\end{array}$} & Organizational structure change & Yes & Enabled owner to focus on marketing strategy and activities \\
\hline & & $5 \mathrm{~S}$ & Partially & Cost and lead time reduction, better installing service \\
\hline & & Suggestion scheme & Yes & Quality improvement \\
\hline & & Strategy dev. and imp. & Yes & Targeted customer section, planned marketing activities \\
\hline & & Website & Yes & Reaching more customers via advertising \\
\hline & & $\begin{array}{l}\text { Collaboration and } \\
\text { networking activities }\end{array}$ & Partially & Reaching more customers via promotion \\
\hline \multirow{5}{*}{ Company B } & \multirow{5}{*}{$\begin{array}{l}\text { Long lead } \\
\text { times as a } \\
\text { barrier to } \\
\text { reaching } \\
\text { more } \\
\text { customers }\end{array}$} & $5 \mathrm{~S}$ & Yes & Cost and lead time reduction \\
\hline & & Suggestion scheme & Yes & Cost and lead time reduction \\
\hline & & Strategy dev. and imp. & Partially & A strategy to teach customers why they should wait \\
\hline & & $\begin{array}{l}\text { Collaboration and } \\
\text { networking activities }\end{array}$ & Partially & $\begin{array}{l}\text { Finding funds to invest new equipment and } \\
\text { produce new products for same customer groups }\end{array}$ \\
\hline & & $\begin{array}{l}\text { Developing } \\
\text { customer engagement }\end{array}$ & Partially & $\begin{array}{l}\text { Teaching customers to make an order in advance to } \\
\text { enable manufacturer for providing goods on time }\end{array}$ \\
\hline \multirow{6}{*}{ Company C } & \multirow{6}{*}{$\begin{array}{l}\text { Cost } \\
\text { competition }\end{array}$} & $5 \mathrm{~S}$ & Yes & Cost and lead time reduction \\
\hline & & SMED & Yes & Cost and lead time reduction \\
\hline & & Suggestion scheme & Partially & Quality improvement, cost reduction \\
\hline & & Customer engagement & Yes & $\begin{array}{l}\text { Customers learned what kind of product choices } \\
\text { increase production and product cost }\end{array}$ \\
\hline & & $\begin{array}{l}\text { Collaboration and } \\
\text { networking activities }\end{array}$ & Partially & $\begin{array}{l}\text { Finding funds to invest new equipment and } \\
\text { produce new products }\end{array}$ \\
\hline & & Strategy dev. And imp. & Yes & $\begin{array}{l}\text { Formulation of new strategy based on } \\
\text { providing right service to customers and it works well }\end{array}$ \\
\hline \multirow{3}{*}{ Company D } & \multirow{3}{*}{$\begin{array}{l}\text { Need to } \\
\text { attract new } \\
\text { customers }\end{array}$} & Strategy dev. and imp. & Yes & $\begin{array}{l}\text { Developing a strategy to provide right } \\
\text { product at right place at right time }\end{array}$ \\
\hline & & Packaging improvement & Yes & Prevented goods to be damaged at transportation \\
\hline & & $\begin{array}{l}\text { Collaboration and } \\
\text { networking activities }\end{array}$ & Yes & $\begin{array}{l}\text { Building new collaborations that enable } \\
\text { goods to be sold in big super markets }\end{array}$ \\
\hline
\end{tabular}

Some findings were derived from data as follows:

Micro enterprises are different than SMEs and Large enterprises. Owner of micro manufacturing enterprises focuses on operational activities rather than strategic activities. Thus, lack of marketing strategy and less marketing activities are common issues in micro manufacturing enterprises. In this study, it was found that owners/managers with more slack time for strategic activities can focus on development and implementation of marketing strategy and marketing activities.

Lack of strategy is identified another issue that prevent micro manufacturing companies to develop marketing capability. It was found that micro manufacturing enterprises can reach more customers with right marketing strategy. 
Low productivity is another common problem that is found in this study in micro manufacturing enterprises. Micro manufacturing enterprises mainly supply products for local and regional markets but they compete with large and SMEs. Micro manufacturers should provide low prices to gain competitive advantage. It was found that continuous improvement activities were applicable and reduced cost in micro manufacturing enterprises. Lower manufacturing cost means more advantage on price competition.

Production capabilities are limited in micro manufacturing enterprises as they cannot purchase newest technology or high volume required machines. Networking and collaboration activities enable them to benefit from other organisations' equipment to increase product range, product quality and reduce production costs. It was found that micro manufacturing enterprises with networking and collaboration activities are able to benefits others equipment and fulfil different customers' requirements.

\section{Discussion}

In conceptual framework, four propositions were tested with this research. In literature, strategy development and implementation has been identified as essential determinant of marketing capability [3] [14] and literature is confirmed in this research as micro manufacturing enterprises requires strategy development and implementation to enhance marketing capabilities. Interesting fact is that micro enterprises fails to formulate marketing strategy and implementation as they mainly focus daily problems. It was found that micro manufacturing enterprises also perform better once a marketing strategy formulated. Furthermore, current literature emphasizes the benefits of networking and collaboration activities for marketing capabilities such as sharing knowledge and technology, accessing new markets via others' distribution channel, and sensing new opportunities [4] [11] [15]. This study confirms to current literature by positive impacts of networking and collaboration activities on marketing capability. In addition, operational performance is linked with marketing performance in literature [3] [4]. Marketing capability requires operational support to increase customer expectation fulfilment and create loyal customer bases. Literature is confirmed with this research as micro manufacturing enterprises face low productivity and long lead time problems, once those problems are solved, they are able to reach more customers to sell more products. Finally, marketing capabilities require specific marketing activities and experienced employees [3] [15]. In micro manufacturing enterprises, employees do not assign for a single area to gain experience. In addition, marketing activities are managed and planned by owner/manager who spends most of his/her time on controlling and commanding operations. It is found that empowerment disables owners/managers to focus on strategic activities and owners/managers with more slack time are able to spend more time on marketing activities which promotes marketing capabilities in micro manufacturing enterprises. This study extends the current literature by 
emphasizing organisation structure and delegating authority promotes marketing capability in micro manufacturing.

\section{Conclusions}

In this research, it is aimed to understand development of marketing capability in micro manufacturing enterprises. The selected methodology provides deep understanding of marketing capability development in micro manufacturing enterprises. Findings of this research provide practical knowledge to develop marketing capability in micro manufacturing enterprises. This research has both theoretical and practical implications for researchers and practitioners. Theoretical contributions to literature are that marketing capability should be considered from system perspective as all other capabilities have direct or indirect relations with marketing capability. Importance of creating slack time for owner/ manager is emphasized with this research to enhance marketing capability in micro manufacturing enterprises. Furthermore, positive impacts of networking and collaboration activities on marketing capability in micro manufacturing enterprises are confirmed in this research. Moreover, it is emphasized that continuous improvement culture and operational excellence increase competitive advantages of micro manufacturing enterprises. Finally, it is confirmed that strategy development and implementation are essential for marketing capability development. Practical implications are as follows: micro manufacturing enterprises require operation excellence trainings to reduce waste in their production process, strategy development training to formulate right marketing strategy, and encourage owners to attend more sectoral meetings and/or expos to find collaboration opportunities.

There are various research limitations and further research suggestions. First limitation of this research is that selected companies are from same region of Turkey and it might have regional and/or cultural effects on findings. Thus, further research can be conducted in different regions of Turkey and another country for comparison studies. Furthermore, propositions are tested with four cases which we cannot strongly imply that findings will definitely work on all micro enterprises. Quantitative research can be conducted to test findings and make general statement on marketing capability development in micro manufacturing enterprises. Finally, we have been collaborated with four companies over 12 months which some interventions such as operational excellence culture require more time than others such as creating website. This data is collected during a time limited research.

\section{References}

[1] Kotler, P., Keller, K., Brady, M., Goodman, M. and Hansen, T. (2009) Marketing Management. Pearson Prentice Hall, Harlow.

[2] Kotler, P. and Keller, K. (2008) Marketing Management. 13th Edition, Prentice Hall, New Jersey.

[3] Santos-Vijande, L., Sanzo-Pérez, M.J., Gutiérrez, J.A., Trespalacios, R. and Nuria, G. 
(2012) Marketing Capabilities Development in Small and Medium Enterprises: Implications for Performance. Journal of CENTRUM Cathedra, 5, 24-42. https://doi.org/10.7835/jcc-berj-2012-0065

[4] Moller, K. and Anttila, M. (1987) Marketing Capability-A Key Success Factor in Small Business? Journal of Marketing Management, 3, 185-203. https://doi.org/10.1080/0267257X.1987.9964038

[5] Gebreeyesus, M. (2007) Growth of Micro-Enterprises: Empirical Evidence from Ethiopia. Ethiopian Development Research Institute (EDR), 1-21.

[6] OECD (2014) Enterprises by Business Size. https://data.oecd.org/entrepreneur/enterprises-by-business-size.html

[7] Beckett, R.C. (2008) Marketing Capabilities under a Collective Brand-Three Longitudinal Case Studies of Australian SME Experience. Small Enterprise Research, 16, 21-31. https://doi.org/10.5172/ser.16.2.21

[8] Perren, L. (1999) Factors in the Growth of Micro-Enterprises (Part 1): Developing a Framework. Journal of Small Business and Enterprise Development, 6, 366-385. https://doi.org/10.1108/EUM0000000006691

[9] O’Dwyer, M. and Ryan, E. (2000) Management Development Issues for Owners/ Managers of Micro-Enterprises. Journal of European Industrial Training, 24, 345353. https://doi.org/10.1108/03090590010373334

[10] Aruna, N. (2015) Problems Faced by Micro, Small and Medium Enterprises-A Special Reference to Small Entrepreneurs in Visakhapatnam. Journal of Business and Management, 17, 43-49.

[11] Ripolles, M. and Blesa, A. (2012) International New Ventures as "Small Multinationals": The Importance of Marketing Capabilities. Journal of World Business, 47, 277-287. https://doi.org/10.1016/j.jwb.2011.04.015

[12] Banterle, A., Carraresi, L. and Stranieri, S. (2010) Small Business Marketing Capability in the Food Sector: The Cases of Belgium, Hungary and Italy. International Journal of Food System Dynamics, 2, 94-102.

[13] Porter, M.E. (1985) Competitive Advantage. The Free Press, New York.

[14] Qureshi, S. and Mian, S.A. (2010) Antecedents and Outcomes of Entrepreneurial Firms Marketing Capabilities: An Empirical Investigation of Small Technology Based Firms. Journal of Strategic Innovation and Sustainability, 6, 28-45.

[15] Qureshi, S. and Kratzer, J. (2011) An Investigation of Antecedents and Outcomes of Marketing Capabilities in Entrepreneurial Firms: An Empirical Study of Small Technology-Based Firms in Germany. Journal of Small Business and Entrepreneurship, 24, 49-66. https://doi.org/10.1080/08276331.2011.10593525

[16] Inan, G.G. and Bititci, U.S. (2015) Understanding Organizational Capabilities and Dynamic Capabilities in the Context of Micro Enterprises: A Research Agenda. Procedia-Social and Behavioral Sciences, 210, 310-319. https://doi.org/10.1016/j.sbspro.2015.11.371

[17] Porter, M.E. (1980) Competitive Strategy. The Free Press, New York.

[18] Reason, P. and Bradbury, H. (2001) Handbook of Action Research: Participative Inquiry and Practice. Sage Publications, Thousand Oaks.

[19] Stringer, E.T. (2013) Action Research: A Handbook for Practitioners. 3rd Edition, Sage Publications, Thousand Oaks.

[20] Susman, G.I. and Evered, R.D. (1978) An Assessment of the Scientific Merits of Action Research. Administrative Science Quarterly, 23, 582-603. https://doi.org/10.2307/2392581 